\title{
SERES HUMANOS, ANIMAIS PEÇONHENTOS E AMBIENTE: CONHECIMENTO PRÉVIO DO PÚBLICO INFANTIL
}

\author{
Yara Gomes Corrêa ${ }^{1}$ \\ Derval Gomes Ribeiro Neto ${ }^{2}$ \\ Taluany Silva do Nascimento ${ }^{3}$ \\ Antônio Ítalo dos Santos Nunes ${ }^{4}$ \\ Carla Simone Seibert ${ }^{5}$
}

Resumo: $O$ avanço dos sistemas urbanos sobre a natureza aumentou a frequência dos encontros entre seres humanos e animais venenosos peçonhentos. O objetivo deste estudo foi diagnosticar o conhecimento prévio de uma comunidade escolar sobre sua relação ambiental com os animais venenosos peçonhentos. Houve pesquisa-ação, com realização de oficinas didático-pedagógicas para crianças, aplicação de questionários e observação não participante. O público se confundiu para classificação dos animais como venenosos peçonhentos e mostrou-se indiferente aos ambientes modificados, entre outros resultados. Concluiu-se que as oficinas foram eficientes para fixar informações morfofisiológicas e ineficazes para sensibilizar as crianças quanto à sua interação ambiental com esses animais.

Palavras-chave: Arraia de Água Doce; Escorpião; Serpente; Ambiente; Educação.

\footnotetext{
1 Universidade Federal do Tocantins (UFT). E-mail: yaragc@mail.uft.edu.br. Link para o Lattes: http://lattes.cnpq.br/0564283397583339.

2 Universidade Federal do Tocantins (UFT). E-mail: derval@mail.uft.edu.br. Link para o Lattes: http://lattes.cnpq.br/0793667599069011.

3 Universidade Federal do Tocantins (UFT). E-mail: taluany15@hotmail.com. Link para o Lattes: http://lattes.cnpq.br/0564283397583339.

4 Universidade Federal do Tocantins (UFT). E-mail: antonio.italo@mail.uft.edu.br. Link para o Lattes: http://lattes.cnpq.br/5183927816478281.

5 Universidade Federal do Tocantins (UFT). E-mail: seibertcs@mail.uft.edu.br. Link para o Lattes: http://lattes.cnpq.br/6679543572745031.
} 
Abstract: He advance of urban systems over nature has increased the frequency of encounters between humans and poisonous venomous animals. The aim of this study was to diagnose the prior knowledge of a school community about its environmental relationship with venomous poisonous animals. There was action research, with didactic-pedagogical workshops for children, application of questionnaires and non-participant observation. The public was confused to classify the animals as venomous venomous and showed itself to be indifferent to modified environments, among other results. It was concluded that the workshops were efficient in fixing morphophysiological information and ineffective in sensitizing children about their environmental interaction with these animals.

Keywords: Freshwater Stingray; Scorpion; Snake; Environment; Education.

\section{Introdução}

A expansão dos sistemas urbanos e das fronteiras agrícolas brasileiras nas últimas décadas vem provocando a retirada de vegetação e acarretando impactos ambientais importantes, tais como: problemas hídricos; aumento da incidência de queimadas; excedentes do campo para o ambiente urbano, gerando mais loteamentos; e o movimento da economia por incremento do agronegócio (IBGE, 2019; SOUZA, 2015; PESSÔA, 1988 E, ainda, encontros cada vez mais frequentes entre seres humanos e animais silvestres, entre eles, os animais venenosos peçonhentos.

Animais venenosos peçonhentos e animais venenosos não peçonhentos diferem entre si. Aqueles com peçonha possuem glândulas de veneno que se comunicam com estruturas inoculadoras do mesmo. Já os animais venenosos não peçonhentos não apresentam estrutura inoculadora, mas podem produzir veneno e provocar o envenenamento por contato, por compressão ou até mesmo por ingestão (BELTRAME; D'AGOSTINI, 2017; COTTA, 2014; BERNARDE, 2012; INSTITUTO BUTANTAN, 2007; FRANÇA, 2003).

A evolução dos animais venenosos peçonhentos selecionou espécies com estruturas inoculadoras de veneno para alimentação e defesa (GOPALAKRISHNAKONE et al., 2015; BARBARO et al., 2007; RUSSEL, 1971), condição essencial para sua existência.

Os animais venenosos peçonhentos coexistem no ambiente junto aos demais animais humanos e não humanos, o qual vem sofrendo grandes modificações. Nesse mesmo cenário, todos buscam acesso a tudo aquilo de que precisam para se manter vivos e íntegros fisicamente, condição para a conservação ambiental (CORRÊA; SEIBERT, 2016). A visão humana em relação aos animais venenosos peçonhentos é instrumentalista e fracionada, está bem ligada à utilidade dos demais animais para sua vida (BARBOSA, 2015; KELLERT, 1984). Portanto, durante os "encontros" entre ambos, na maioria das vezes, os animais não humanos são prejudicados, ou ainda mortos (OLIVEIRA et al., 2015).

Revbea, São Paulo, V. 16, № 6: 31-51, 2021. 
A informação e a sensibilização por meio da educação em todos os níveis vêm sendo sugeridas por estudiosos desses animais (FREITAS et al., 2020; AZEVEDO; ALMEIDA, 2018; CORRÊA; SEIBERT, 2016; MEYER; DA SILVA, 2008). Há convergência entre estudiosos da educação de que as crianças trazem consigo suas próprias compreensões do ambiente, conhecimento prévio adquirido a partir de suas experiências (BELLUCO; CARVALHO, 2014; MESSEDER NETO; PINHEIRO; ROQUE, 2013; SANTOS, 2012).

Com isso, devido às condições relativas à morfologia evolutiva de inoculação da peçonha e ao aumento dos encontros dos animais venenosos peçonhentos com seres humanos (SINAN, 2017), destacam-se três grupos específicos que se revelam conflitantes em suas relações com seres humanos no presente estudo: arraias de água doce (LAMEIRAS et al., 2013; GARRONE NETO; HADDAD JÚNIOR, 2010; GARRONE NETO; SAZIMA, 2009; HADDAD JÚNIOR et al., 2004; HADDAD JÚNIOR, 2000; HALSTEAD, 1970), escorpiões (OLIVEIRA et al., 2020; ESPOSITO et al., 2017; GOPALAKRISHNAKONE et al., 2015; BRANDÃO; FRANÇOSO, 2010; MARTINS et al., 2008; SCHMIDT, 2008; CARDOSO, 2003) e serpentes (COSTA; BÉRNILS, 2018; MONACO; MEIRELES; ABDULLATIF, 2017; BERNARDE, 2014; FREITAS, 2003).

Como proposta para o enfrentamento desse problema ambiental, sobretudo quando realizada para o público mais jovem, emerge-se o problema central desta pesquisa: qual seria o conhecimento prévio da comunidade escolar sobre sua relação com os animais peçonhentos? E ainda as seguintes questões: quais informações são sabidas por esse público? Quais não são? Poder-se-iam indicar possíveis intervenções para veicular as informações necessárias a essa comunidade?

Diante disso, objetivou-se diagnosticar o conhecimento prévio da comunidade escolar local sobre sua relação ambiental e informação relativa aos animais venenosos peçonhentos, sobretudo escorpiões, serpentes e arraias de água doce, com a finalidade de nortear premissas para a elaboração de materiais didático-pedagógicos que possam intervir em prol da conservação ambiental.

\section{Desenho metodológico}

Admitindo-se que a demanda não partiu necessariamente da comunidade escolar, mas que se legitimou e foi validada por ela desde seu início, foi realizada uma "pesquisa-ação", com abordagem qualiquantitativa, conforme Gil (2010), aqui escolhida por propor mecanismos calcados na ciência, a partir da prática extensionista (CORREA; SEIBERT, 2019; PICHETH; CASSANDRE; THIOLLENT, 2016; PEREIRA, 2012; THIOLLENT, 2011; ALMEIDA; NUNES, 2010; FRANCO, 2005; BARBIER, 2007; ENGEL, 2000. Bonassina e Kuroshima (2021) concluíram que a extensão universitária 
associada à pesquisa é uma ferramenta na busca por soluções relativas às questões ambientais, demandadas pela educação contemporânea.

A pesquisa-ação é um método norte-americano preconizado por Kurt Lewin, psicólogo alemão, naturalizado como americano. Ela precedeu a Segunda Guerra Mundial e se consolidou a partir da década de 1960, sobretudo na Europa. Como herança neolewiniana, a porção "ação" foi ganhando destaque sobre a porção "pesquisa", sendo cada vez mais orientada por meio da participação da comunidade envolvida, que permite a exploração para fins de pesquisa mais acadêmica (BARBIER, 2007).

Para desenvolvê-la, são necessárias: a) identificação do problema e sua contextualização; b) planejamento e realização em espiral, dependente de desapego por parte de quem a desenvolve, exigindo desprendimento por parte do seu condutor para aceitar os rumos que o processo pode tomar; c) escolha das técnicas da pesquisa-ação, sobretudo as relacionadas à aceitação do grupo, à observação participante e ao diário de anotações; e, por fim, d) sistematização do conhecimento a partir da tríade: teorização, avaliação e publicação dos resultados (BARBIER, 2007).

Dito isso, na presente pesquisa-ação, houve facilidade de contato e legitimação da comunidade escolar envolvida por afinidade e reconhecimento do objeto estudado como um problema ambiental, fato que facilitou a formalização do trabalho.

\section{Área de estudo}

A área do estudo compreendeu o município de Porto Nacional, Tocantins, cuja localização está representada na Figura 1. Para essa localidade, foram identificados dados estatísticos crescentes de registros de agravos, decorrentes dos encontros cada vez mais frequentes entre seres humanos e animais venenosos peçonhentos, sobretudo arraias de água doce, escorpiões e serpentes, revelando uma área de estudo importante para a compreensão do problema e para identificação da proposição de medidas ligadas à educação ambiental preventiva. 


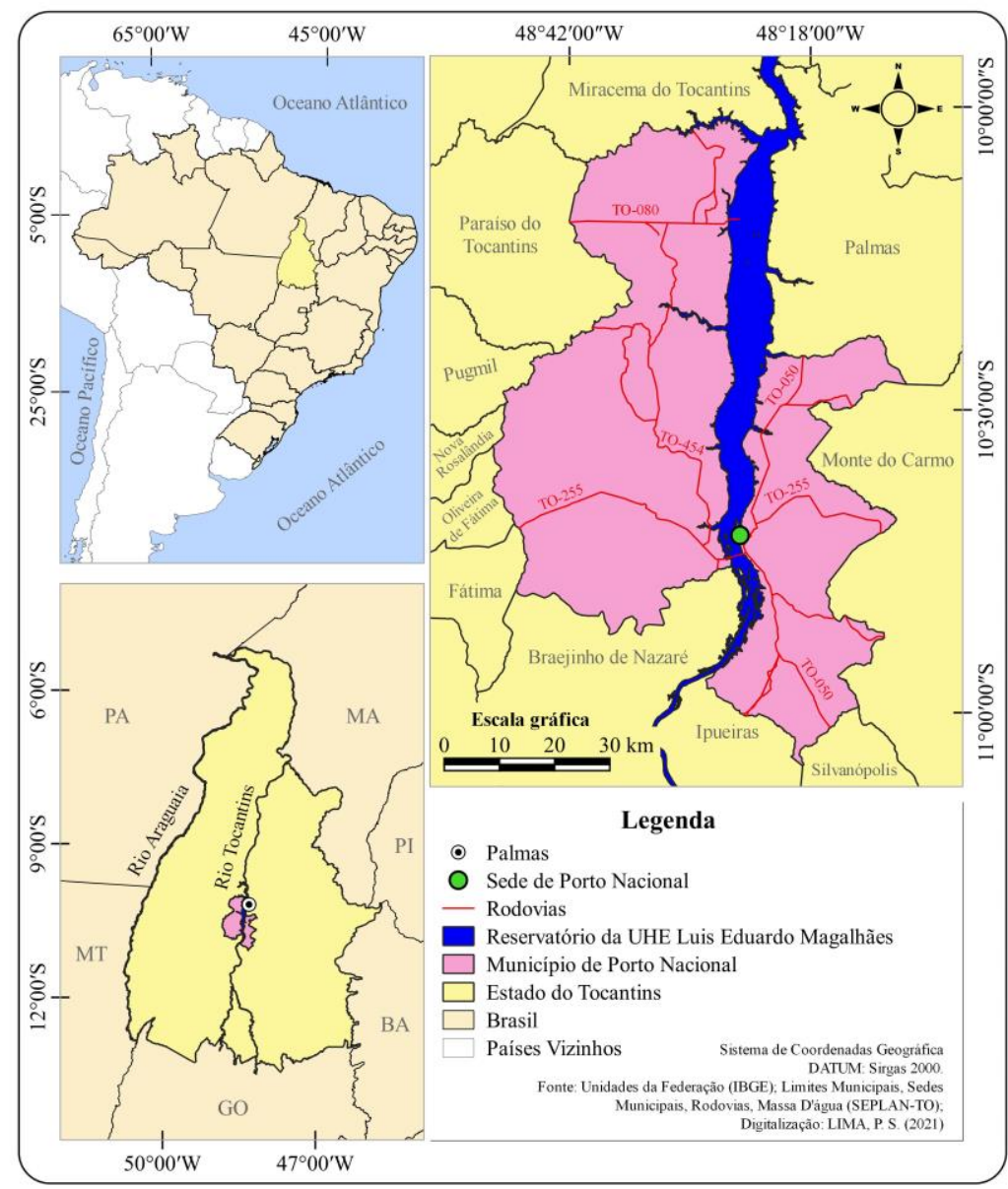

Figura 1: Localização do município de Porto Nacional - TO.

Fonte: Unidades da Federação (IBGE). Limites Municipais, Sedes Municipais, Rodovias, Massa D'água (SEPLAN-TO). Digitalização: LIMA, P.S. (2021).

\section{Comunidade envolvida}

Para o levantamento dos conhecimentos prévios, o público-alvo, no caso, a comunidade escolar envolvida nesta pesquisa-ação, compreendeu 217 estudantes do $5^{\circ}$ ano da Educação Básica de quatro escolas da rede pública de ensino municipal de Porto Nacional - EM, matriculados em 2018: EM A, EM $\mathrm{B}, \mathrm{EM} \mathrm{C}$ e EM D, aqui com os nomes preservados.

Entre os pré-requisitos da comunidade envolvida, observou-se o grupo de crianças com certo domínio cognitivo da língua portuguesa, já estabelecido na maioria dos casos que corresponde à faixa etária entre 10 e 12 anos de idade, além disso, moradores das áreas urbanas e periurbanas do município, locais que correspondem à problemática apresentada. Esse público é mais propenso à sensibilização quanto a esse tipo de questão ambiental (PRUDENTE, 2013), conforme evidenciado em estudo semelhante (CORRÊA; SEIBERT, 2019). 


\section{Amparo legal e ético}

Delimitadas a área de estudo e a comunidade envolvidas na pesquisaação, procedeu-se à sua formalização, cujo amparo legal relativo às questões éticas foi resguardado pela Lei $n^{\circ}$ 10.406, de 10 de janeiro de 2002, Art. 5ㅇ e 20 (BRASIL, 2002).

Este Artigo prevê que, no ato da matrícula, o pai ou responsável pelo estudante autoriza a utilização de sua imagem e/ou áudio e escrita para utilização em propagandas sem fins lucrativos e/ou pesquisas. Portanto, a figura dos diretores das unidades escolares, aceitando os respectivos pedidos formais, garantiu a isenção de possíveis problemas relativos aos aspectos éticos que pudessem ser levantados. Esse recurso foi aceito em publicações similares recentes (RIBEIRO NETO et al., 2020; CORRÊA; SEIBERT, 2019; BRASIL, 2002).

\section{Etapas metodológicas da pesquisa-ação}

Admitindo-se que o diálogo permanente com a comunidade e as idas e as vindas ou ainda a mudança do curso da pesquisa sejam típicos desse tipo de pesquisa, pôdem-se discriminar três importantes etapas para seu início: 1) aplicação de um questionário pré-oficina e análise para nortear elaboração de oficinas didático-pedagógicas; 2) realização de oficinas didático-pedagógicas para: a) comparar animais venenosos peçonhentos e animais venenosos não peçonhentos; b) caracterizar, mais especificamente as arraias de água doce, os escorpiões e as serpentes, quanto aos seus respectivos aspectos morfofisiológicos, evolutivos e ecológicos; e c) disponibilizar informações sobre cuidados preventivos e orientar a busca para o tratamento adequado, diante de possíveis encontros entre seres humanos e animais peçonhentos, bem como sobre cuidados relativos à integridade dos próprios animais; e 3) aplicação de um questionário pós-oficina e análise para determinação das premissas para revelar a eficácia das oficinas realizadas e indicar possibilidades de intervenção futura.

Além disso, como característica de uma pesquisa-ação, houve utilização das técnicas metodológicas de observação participante predominantemente existencial e adoção de bloco de anotações (BARBIER, 2007), permeando o processo como um todo.

\section{Aplicação dos questionários pré e pós-oficinas temáticas}

Para a aplicação dos questionários, elaboraram-se dois instrumentos. $\mathrm{O}$ questionário pré-oficina foi diagnóstico e exploratório sobre os conhecimentos prévios da comunidade, continha sete questões, sendo cinco fechadas e duas abertas. O questionário pós-oficina avaliou a eficácia das oficinas, possuía duas questões abertas. 
Os resultados coletados a partir das respostas das crianças aos questionários antes e depois das oficinas temáticas foram tabulados em planilhas do Microsoft Excel e processados pelo software livre Interface de $R$ pour les Analyses Multidimensionnelles de Textes et de Questionnaires IRaMuTeQ, versão 0,7 alpha 2.

A tradução dos corpora (do latim: plural de corpus) da pesquisa foi qualitativa e gerou nuvens de palavras e análise de similaritude (BRITO, 2019). Os resultados sobre os conhecimentos prévios foram usados para elaboração das oficinas temáticas, e os resultados coletados após essa intervenção avaliaram tais oficinas e sinalizaram sugestões de mecanismos de intervenção para serem realizados a posteriori.

Em ambos os questionários, antes e pós as oficinas, foi solicitado às crianças participantes que escolhessem e desenhassem um dos três animais venenosos peçonhentos enfocados neste estudo, da seguinte forma: 1) préoficinas: "Opte por um dos animais abaixo, desenhe o animal no ambiente onde vive. Escreva o nome das partes do animal, aquelas que você lembrar. () Arraias; ( ) Escorpiões; ( ) Serpentes."; e 2) pós-oficinas: "Hoje você aprendeu muitas coisas, então desenhe o animal (serpente, escorpião ou arraia de água doce) no ambiente onde ele vive. Escreva o nome das partes do corpo do animal, aquelas que você lembrar.".

Os resultados obtidos por meio dos desenhos foram analisados qualiquantitativamente e classificados quanto aos aspectos relacionados ao nível de interação ambiental das crianças com os animais venenosos peçonhentos, a partir de quatro categorias, níveis de 1 a 4 (BARDIN, 2011), a saber: Nível 1 (N1): presença apenas do animal venenoso peçonhento, sem elementos constituintes do ambiente, seja natural ou modificado; Nível 2 (N2): presença do animal venenoso peçonhento e de elementos constituintes do ambiente natural, sem elementos que representam a presença humana; Nível 3 (N3): presença do animal venenoso peçonhento, de elementos constituintes do ambiente natural e de elementos que representam a presença humana com interação menos positiva em relação ao animal; e Nível 4 (N4): presença do animal venenoso peçonhento, de elementos constituintes do ambiente natural $\mathrm{e}$ de elementos que representam a presença humana, com interação mais positiva em relação ao animal.

Houve, portanto, análise qualitativa com subjetivação para o julgamento e identificação dos desenhos, seguida da determinação quantitativa dos desenhos classificados, por categoria (nível), apresentada e analisada na forma de gráfico de barras por meio do Microsoft Excel. 


\section{Oficinas didático-pedagógicas temáticas}

Para a preparação e realização das oficinas temáticas, consideraram-se os resultados dos conhecimentos prévios da comunidade envolvida, com preparação de material didático-pedagógico lúdico, confeccionado com sucatas; banners e folders; e, ainda, com exemplares de animais peçonhentos fixados, organizados e cedidos pela Universidade Federal do Tocantins (UFT), Campus de Porto Nacional - TO. Foram realizadas três oficinas, uma para cada grupo de animais peçonhentos estudados: arraias de água doce, escorpiões e serpentes.

As oficinas temáticas desenvolvidas nos contextos educacionais se constituem como uma técnica de intervenção bem eficiente. Estudos similares produziram reflexão sobre os problemas comunitários comuns, estimulando o grupo a assumir um papel importante em seu autocuidado e cuidado com o meio ambiente (NASCIMENTO; SANTOS; NUNES, 2019; CORRÊA; SEIBERT, 2019).

As oficinas temáticas objetivaram: a) problematizar os conhecimentos prévios dos sujeitos participantes no tocante aos objetos de estudo; b) levantar as informações conhecidas e não conhecidas pela comunidade; c) sensibilizar a comunidade participante; e d) levantar possíveis mecanismos de intervenção em prol da melhoria das relações entre seres humanos e animais venenosos peçonhentos.

A execução das oficinas ocorreu entre os meses de setembro e novembro de 2018. Em cada escola, subdividiram-se os sujeitos participantes em três subgrupos, os quais receberam cada qual uma das oficinas temáticas, concomitantemente. Todas com duração aproximada de uma hora. Ao final, houve exposição dos materiais didático-pedagógicos e dos exemplares fixados nas áreas livres das escolas para todas as crianças e profissionais educacionais presentes.

Como técnicas para desenvolvimento das oficinas temáticas, utilizaramse (Figura 2, A a D): a) atividade disparadora por meio do quadro de diferenciação entre animais não venenosos, venenosos não peçonhentos e venenosos peçonhentos; b) aula expositiva sobre morfofisiologia, evolução, ecologia e cuidados gerais em relação aos encontros com os animais venenosos peçonhentos estudados, usando banners e folders pré-elaborados; c) exposição de exemplares fixados; e d) contação livre de histórias pelas crianças, com apoio de cenário de sucatas e fantoches de palito, que se mostrou interessante em Corrêa, Seibert (2019) e em Moreira e Marandino (2015).

Foram preparadas três oficinas temáticas, uma para cada animal peçonhento abordado (arraias de água doce, escorpiões e serpentes), todas se valendo, inicialmente, de argumentos e procedimentos padrões, relativos à abertura das oficinas e à comparação entre animais venenosos peçonhentos e animais venenosos não peçonhentos. $\mathrm{E}$, posteriormente, diferiu-se umas das outras quanto à ênfase em relação ao respectivo animal venenoso peçonhento: arraias de água doce, escorpiões e serpentes. 
Ao final, disponibilizou-se para cada tema (arraia de água doce, escorpião e serpente) um cenário previamente confeccionado pelos oficineiros, contendo seus respectivos ambientes naturais e, ainda, fantoches de palito com os personagens de seres humanos e dos animais envolvidos nas abordagens. A partir daí procedeu-se a gravação de áudio e as anotações em caderneta.

A.

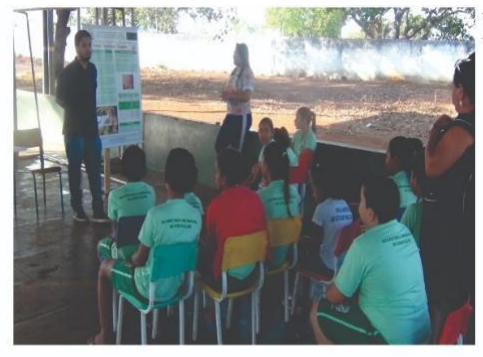

C.

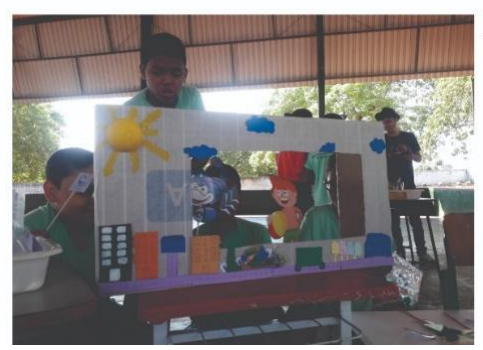

B.

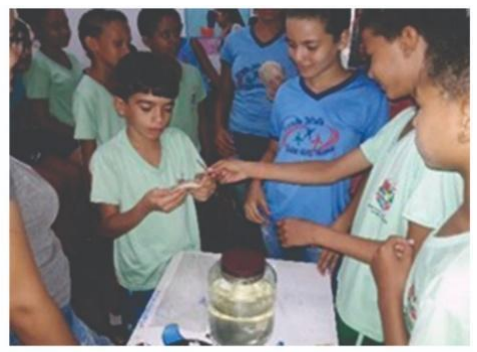

D.

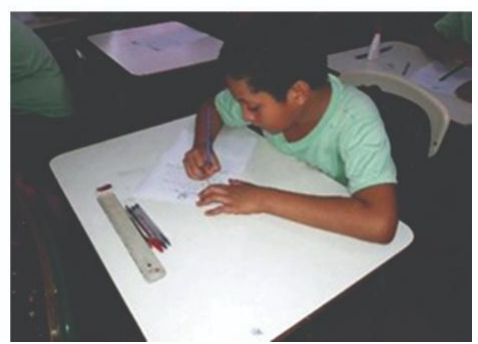

Figura 2: A: Atividade em aula expositiva sobre diferenciação entre animais não venenosos, animais venenosos não peçonhentos e animais venenosos peçonhentos; $\mathrm{B}$ : Contato com exemplares fixados; C: Contação de histórias; D: Aplicação dos questionários.

Fonte: Da pesquisa (2021).

\section{Resultados e discussão}

\section{Conhecimentos prévios da comunidade, anterior às oficinas temáticas}

A nuvem de palavras gerada pelo corpus geral da pesquisa $(n=576)$ a partir das respostas dadas à pergunta feita antes das oficinas realizadas com a comunidade escolar - "Qual desses animais possui veneno?", com as seguintes opções de resposta: piranha, arraia, serpente, escorpião, aranha, unicórnio, papagaio, sapo, lagarto, baiacu e galinha (Figura 3).

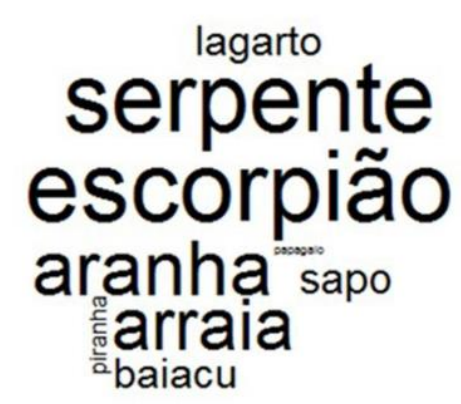

Figura 3: Animais que possuem veneno na percepção da comunidade ouvida, antes das oficinas didático-pedagógicas; corpus geral $(n=576)$; frequência obtida a partir das respostas dadas: escorpião $(n=124)$, serpente $(n=120)$, aranha $(n=91)$, arraia $(n=86)$, sapo $(n=47)$, lagarto $(n=44)$, baiacu $(n=43)$, piranha $(n=18)$, papagaio $(n=3)$, unicórnio $(n=0)$ e galinha $(n=0)$. Fonte: Da pesquisa (2021). 
Ressalta-se que o termo "veneno" foi empregado nessa fase por entender-se que as crianças o compreenderiam melhor. No questionário pósoficina, após se ter trabalhado as diferenças entre animais não venenosos, animais venenosos não peçonhentos e animais venenosos peçonhentos, empregou-se o termo "peçonha".

A maioria das crianças participantes da pesquisa no período pré-oficinas ( $n=421$ ) revelou que "escorpião", "serpente", "aranha" e "arraia" são os animais mais venenosos do portfólio apresentado. Elaboraram-se nuvens de palavras para essa questão, por escolas municipais, no entanto, a análise compartimentalizada não se mostrou relevante para esse contexto. Esses resultados reforçam a necessidade da pesquisa em relação aos objetos do presente estudo na cidade como um todo.

Apesar de não se fazer menção específica aos "animais peçonhentos" no questionário anterior às oficinas, os animais mais mencionados foram os peçonhentos. No entanto, verificou-se alta frequência de respostas para animais venenosos não peçonhentos $(n=134)$, tais como: "sapo", "lagarto" e "baiacu", animais que envenenam por contato ou por sua ingestão.

Estudos relacionados ao medo que seres humanos sentem em relação especificamente aos lagartos revelaram que a valorização do conhecimento popular e o esclarecimento das concepções equivocadas precisam ser estimulados ao longo da Educação Básica, no sentido de evitar-se a propagação de relações conflituosas entre ambos (PASSOS et al., 2015).

A presença da "piranha" e do "papagaio", apesar de pouco citados $(\mathrm{n}=$ 21), demonstra o medo e a preocupação com as ofensas aos seres humanos por parte dos participantes, muito embora não sejam animais venenosos nem peçonhentos, podem causar ferimentos importantes, prováveis memórias coletivas. Sabe-se que o conhecimento prévio dos seres humanos possui correlação direta com as tradições/cultura transmitidas ao longo das gerações, sobrevivendo na memória coletiva (ALEGRO, 2008).

A análise de similaritude proporcionou a identificação e a percepção da intensidade do corpus textual coletado a partir das respostas às demais perguntas do questionário pré-oficinas (Figura 4). Ela diferencia as partes comuns e as especificidades em função das variáveis ilustrativas (descritivas) que foram identificadas na análise (MARCHAND; RATINAUD, 2012).

Observou-se que os locais que costumam frequentar, se sabem dizer se alguém foi ferido por uma serpente, uma arraia ou um escorpião e o que deveria ser feito em caso de acidente aparecem interligados na análise de similaritude na Figura 4. O que fariam se encontrassem com um desses animais não apareceu interligado aos demais campos. 

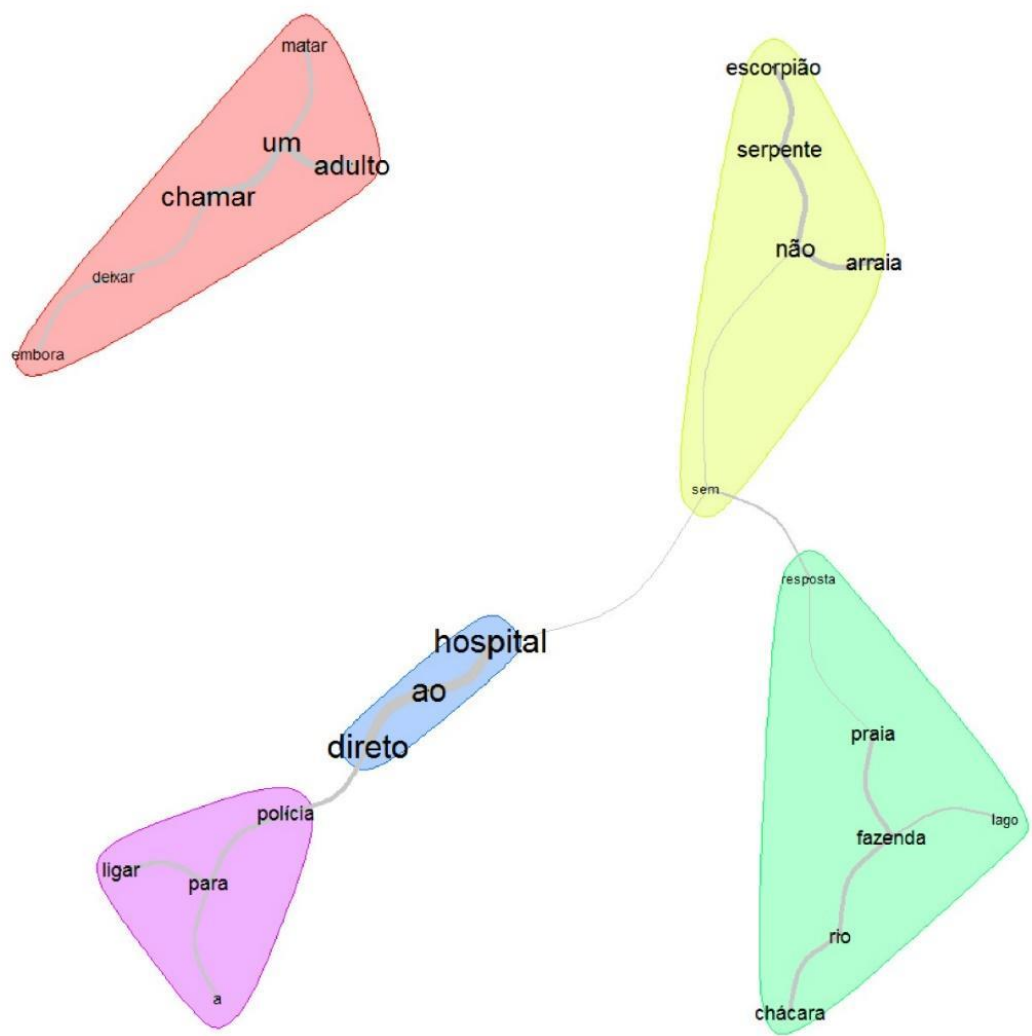

Figura 4: Resultados da análise de similaritude a partir dos dados coletados no questionário pré-oficinas, aplicado ao público-alvo $(\mathrm{n}=120)$.

Perguntas/Opções de resposta/Legenda:

a) "Que lugares você costuma frequentar?", representada pela cor verde;

b) "Conhece alguém que se feriu com uma serpente, um escorpião ou uma arraia?", em amarelo, para todos que marcaram "Sim, escorpião, serpente ou arraia" ou que marcaram

"Não";

c) "O que acha que deve ser feito em caso de acidente?", em azul e lilás; e

d) "O que faria se encontrasse uma serpente, um escorpião ou uma arraia?", em vermelho.

Fonte: Da pesquisa (2021).

O público abordado revelou que frequenta fazendas, chácaras e praias de água doce, muito provavelmente os ambientes em que podem encontrar serpentes, escorpiões e arraias de água doce. $\mathrm{E}$ as opções mais recorrentes em caso de acidentes foram "Ir direto ao hospital" e "Ligar para a polícia".

"Chamar um adulto", "Matar" e "Deixar ir embora" foram, em ordem decrescente, as respostas que mais apareceram para "O que faria se encontrasse uma serpente, um escorpião ou uma arraia?". Esse resultado confirmou a condição conflituosa estudada.

Contudo, os pontos de atenção contemplados para elaboração e realização das oficinas didático-pedagógicas em face da análise dos resultados dos conhecimentos prévios das crianças foram a inclusão de: a) diferenciação entre animais peçonhentos e animais venenosos não peçonhentos; b) 
informações científicas sobre morfofisiologia, evolução e ecologia dos animais peçonhentos: arraias de água doce, escorpiões e serpentes; e c) inclusão de informações científicas sobre cuidados gerais quando houver encontro frequente com esses animais.

\section{Oficinas didático-pedagógicas temáticas}

A atividade disparadora que iniciou as intervenções didáticopedagógicas indagou as crianças sobre seu conhecimento, solicitando que identificassem os animais não venenosos, animais venenosos não peçonhentos e animais venenosos peçonhentos, por meio de um quadro comparativo fixado na lousa da sala de aula e de figuras com vários tipos desses animais.

A análise das anotações geradas a partir da observação participante dessa atividade e a resposta à questão 1 do questionário pós-oficinas (Figura 5) revelou haver confusão relativa à classificação desses animais quanto à presença ou não da peçonha

As aulas expositivas tiveram como pano de fundo as características morfofisiológicas, evolutivas, ecológicas das arraias de água doce, dos escorpiões e das serpentes, bem como aspectos ligados aos cuidados a serem tomados, caso ocorresse o encontro com algum deles. Elas se mostraram bem eficientes, sobretudo ao se comparar os desenhos representados nos questionários anteriores e posteriores às oficinas.

A exposição dos exemplares fixados desses animais complementou as aulas expositivas e serviu para aproximar e desmistificá-los, apesar do medo estar presente na manifestação dos gestos das crianças, como não querer usar luvas para tocá-los ou se esconder atrás de outros colegas.

Observou-se que a introdução de informações científicas, sobretudo em relação às características morfofisiológicas, foi fixada pelo contato com os exemplares dos animais estudados. Constatou-se ainda que as informações sobre a evolução e a ecologia desses animais contribuíram para argumentar um cenário mais conservacionista do ambiente, a partir de uma relação mais consciente entre seres humanos e animais peçonhentos. No entanto, não se observou apropriação de discursos, por parte das crianças, que defendessem a coexistência entre ambos.

Os registros realizados na caderneta de anotações, bem como a reprodução dos áudios gravados durante a contação espontânea de histórias pelas crianças participantes ao final das oficinas revelaram que: a) a confusão para diferenciar animais não venenosos, animais venenosos não peçonhentos e animais venenosos peçonhentos persistiu na fala das personagens; $b$ ) houve precariedade de informações científicas sobre a ecologia e a evolução dos animais venenosos peçonhentos estudados, as quais praticamente não foram reproduzidas nas histórias criadas pelos participantes; e c) ocorreu dificuldade 
de argumentação em defesa da coexistência entre seres humanos e animais venenosos peçonhentos de forma a contribuir para a conservação ambiental.

Portanto, esses resultados revelaram que as oficinas realizadas foram eficientes ao desvelar as características morfofisiológicas dos animais abordados, o mesmo ocorrido durante oficinas de educação ambiental realizadas por Stedile, Camardelo e Cioato (2021). Porém, não se mostraram eficientes para sensibilizar as crianças ao ponto de não verbalizarem a necessidade ou ao menos a possibilidade de coexistência entre seres humanos e animais peçonhentos, de modo a contribuir para a conservação do ambiente na mesma perspectiva de Trajano (2010), isto é, preservando amostras representativas da biodiversidade, seus processos e padrões.

\section{Aplicação do questionário pós-oficinas temáticas}

A nuvem de palavras gerada pelo corpus geral da pesquisa $(n=507)$ a partir das respostas dadas à questão 1 feita após as oficinas à comunidade participante "Cite 4 animais peçonhentos", sem opções de resposta está representada na Figura 5.

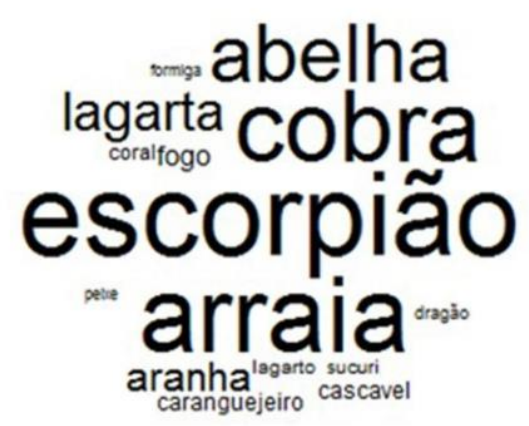

Figura 5: Animais mais apontados como peçonhentos pela comunidade participante, após realização das oficinas didático-pedagógicas; corpus geral $(n=507)$.

Fonte: Da pesquisa (2021).

As palavras mais frequentes, em ordem decrescente, foram "escorpião", "arraia", "cobra" e "abelha". Os três primeiros citados como animais peçonhentos foram justamente aqueles trabalhados durante as oficinas, reiterando o objeto de estudo "relação ambiental entre seres humanos e escorpiões, arraias e serpentes". Para além disso, esse dado indicou outro grupo de animais a serem estudados futuramente, as abelhas.

Notou-se que, na nuvem que antecedeu as oficinas (Figura 3), a palavra "serpente" foi listada como uma opção de resposta, no entanto, quando pósoficinas as mesmas crianças ficaram livres para apontar as palavras, fizeram com bastante frequência para o mesmo grupo animal, porém utilizando a nomenclatura popular "cobra", assunto que merece ser contemplado em futuros mecanismo interventores do processo. 


\section{Representação implícita nos desenhos da comunidade antes e depois das oficinas didático-pedagógicas}

Do universo da pesquisa, $n=217$, obteve-se o índice de retorno de questionários com desenhos de $55,29 \%(n=120)$ para os resultados préoficinas. Acredita-se que isso se deveu à falta dos estudantes no dia em que foram realizadas ou ainda ao fato de não se sentirem à vontade para desenhar. O índice para os resultados pós-oficinas foi de $36,40 \%(n=79)$, muito provavelmente devido estão expressos na Figura 6A.

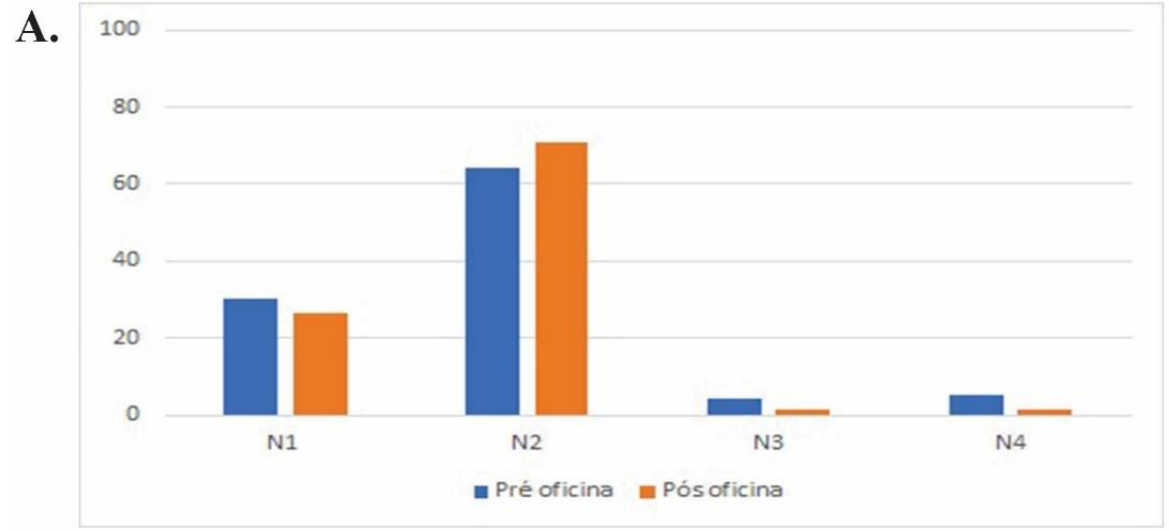

B.

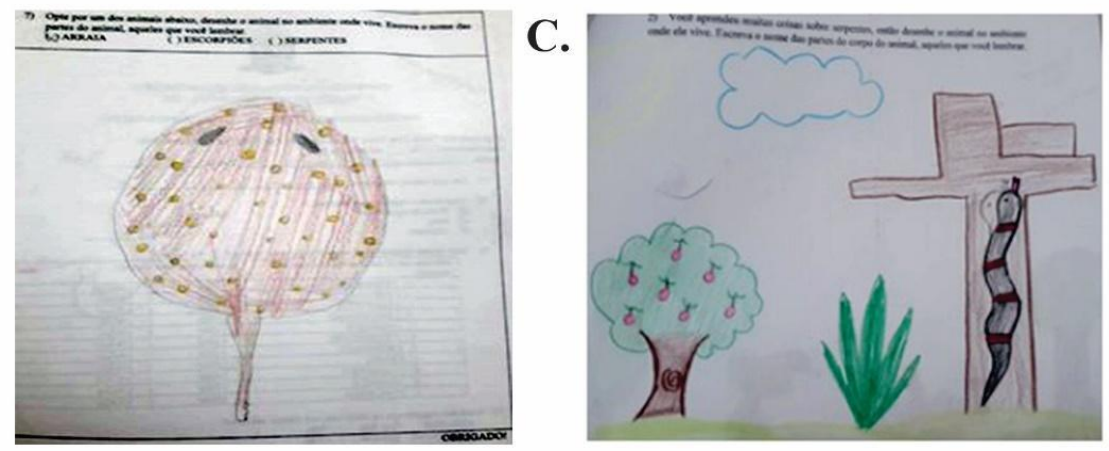

D.

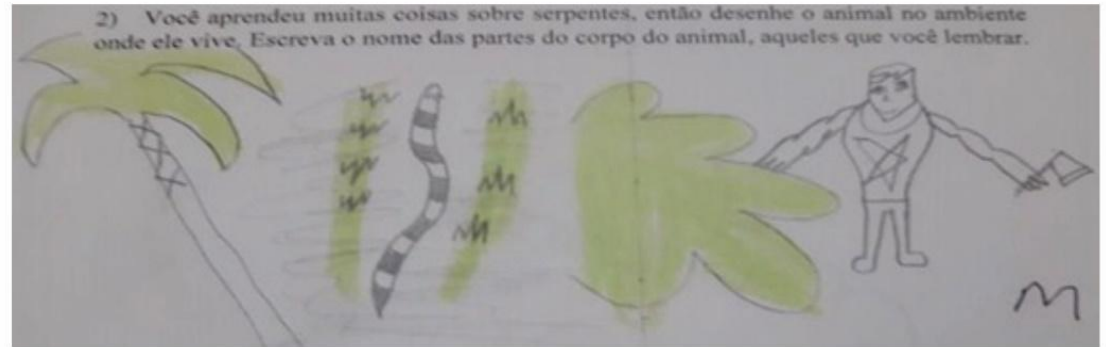

Figura 6 (A a D): A: Resultados da análise dos desenhos elaborados pelo público-alvo antes e depois das oficinas. Legenda: N1: animal sozinho; N2: animal e elementos do ambiente natural;

N3: animal, elementos do ambiente natural e da presença humana com interação menos positiva; N4: animal, elementos do ambiente natural e da presença humana com interação mais positiva. B: Desenho que representa o nível 1 (N1) em que o animal escolhido (arraia de água doce) pelo participante aparece sozinho. C: Desenho representando a relação entre a serpente e simbologias de cunho religioso. D: Desenho classificado no nível 3 (N3) em que o animal escolhido (serpente) é representado em seu ambiente natural, com a presença humana interagindo de forma não conservacionista em relação ao ambiente. Fonte: Da pesquisa (2021). 
Os resultados indicaram que as oficinas foram pouco eficazes para sensibilizar as crianças participantes quanto à interação ambiental entre seres humanos e os animais venenosos peçonhentos, porém bastante eficazes para indicar a presença velada do conflito ambiental estudado, bem como para informar ao público sobre as características morfofisiológicas desses animais, condição que permite a construção de uma narrativa argumentativa mais consistente para proposições futuras de mecanismos mitigadores do problema aqui confirmado. Corroborando com esses resultados, Piaget (1964, p. 12) afirma que:

Só depois de examinarmos os problemas da imitação, do jogo e do pensamento simbólico "inconsciente" poderemos, [...] situar nesse conjunto os primórdios da representação cognitiva e extrair as conclusões a que nos terão conduzido essas análises prévias, no tocante ao mecanismo da atividade representativa ou da função simbólica.

O ambiente natural foi lembrado mais sensivelmente após a realização das intervenções didático-pedagógicas nessa etapa da pesquisa, porém a relação entre os seres humanos e animais venenosos peçonhentos foi pouco representada. Ambientes modificados sequer foram citados e, por isso, nem entraram nas categorias de análise.

O público-alvo, na maioria dos casos, optou por desenhar um dos três animais (arraia, serpente ou escorpião) no ambiente natural, 30,00\% antes e $26,58 \%$ após as oficinas; ou sozinho, $64,16 \%$ nas pré e $70,88 \%$ nas pósoficinas; alterando pouco esse resultado em ambos os testes, quando comparados os resultados pré e pós-oficinas (Figura 6B).

Não se constituiu um objetivo das intervenções realizadas identificar o animal peçonhento mais escolhido pelas crianças para os desenhos, porém, alguns desenhos envolvendo as serpentes e a cruz chamaram a atenção, indicando representações simbólicas de cunho religioso em relação a esses animais (Figura 6C).

Os fatores culturais ou a falta de conhecimento influenciam na forma depreciativa como o ser humano se relaciona com aquilo que o cerca. $\mathrm{E}$, nesse contexto, as serpentes, aliadas ao fato de serem venenosas, são constantemente associadas àquilo que é maligno, contribuindo para uma interação negativa entre ser humano e animal, que por vezes ocasiona a morte das serpentes (FREITAS et al., 2020).

Estudos similares a partir da educação ambiental revelaram ser possível a mudança de postura das crianças em relação aos animais vistos por um olhar de medo, passando-se a um olhar de respeito à biologia das serpentes e de reconstrução das visões do senso comum construídas ao longo da vida, sendo de caráter místico, religioso e até mesmo de barreira pessoal (RIBEIRO-NETO et al., 2020; SILVA et al., 2016). 
A necessidade de se desenvolver um mecanismo mais robusto para sensibilizar o público-alvo ficou bem evidente ao analisar os índices obtidos a partir dos desenhos classificados nos níveis 3 e 4 (N3 e N4), os quais representaram o animal escolhido, elementos do ambiente natural e a presença humana com interação menos positiva (N3: 4,16\% antes e 1,26\% após as oficinas (Figura 6D); e com a presença humana com interação mais positiva em relação aos animais escolhidos (N4: 5,00\% nas pré e 1,26\% nas pós-oficinas).

\section{Conclusões}

Pode-se concluir que a comunidade escolar participante: a) reconheceu que os animais "venenosos peçonhentos", antes e depois das oficinas, foram as serpentes, os escorpiões e as arraias de água doce; b) a maioria revelou conhecer alguém que se feriu em decorrência de encontros com serpentes, escorpiões e arraias; c) confirmou o costume de frequentar ambientes naturais, os quais corroboram para o encontro com animais venenosos peçonhentos; d) revelou não reconhecer as modificações sofridas pelo ambiente natural; e) mostrou-se dividida em relação à atitude mais adequada quando ocorre o encontro com tais animais; e f) evidenciou tímida interação ambiental com os animais venenosos peçonhentos e, quando a houve tal evidência, foi representada com desvantagem para os animais em questão.

Notou-se que as oficinas didático-pedagógicas não foram suficientes para sensibilizar as crianças. Isso indica que as informações científicas sobre os aspectos morfofisiológicos, ecológicos e evolutivos dos animais venenosos peçonhentos em estudo devem ser contempladas como parte da estratégia argumentativa para o desenvolvimento de futuros mecanismos interventores a serem propostos.

\section{Agradecimentos}

Às colaboradoras técnicas Lorrayne Martins e Katiele Cavalcante Viana. À Diretoria Regional de Ensino de Porto Nacional - TO. Ao Edital da PróReitoria de Extensão (PROEX 56/2018) da Universidade Federal do Tocantins (UFT). Ao Programa de Pós-Graduação em Ciências do Ambiente (PPGCiamb), por meio do Programa de Apoio à Pesquisa (PROAP). À Coordenação de Aperfeiçoamento de Pessoal de Nível Superior (CAPES), Edital PROCAD 2013, por meio do Projeto Fortalecimento de Programas de Pós-Graduação na Amazônia e na Extra-Amazônia, com ênfase em envenenamentos ofídicos: uma estratégia de formação de pessoal e interdisciplinaridade. Ao Instituto Federal do Tocantins (IFTO), Campus de Porto Nacional - TO. 


\section{Referências}

ALEGRO, R.C. Conhecimento prévio e aprendizagem significativa de conceitos históricos no Ensino Médio. 2008. 239f. Tese (Doutorado em Educação) Programa de Pós-Graduação em Educação, Universidade Federal de Marília.

ALMEIDA, E. F. de A.; NUNES, J. R. da S. Educação ambiental e ecoturismo em área natural: um estudo de caso no mirante camping e lazer no município. UNICiências, Tangará, MT, v.14, n. 2, 2010.

AZEVEDO, B.R.M.; ALMEIDA, Z. da S. de. Percepção ambiental e proposta didática sobre a desmistificação de animais peçonhentos e venenosos para os alunos do Ensino Médio. Acta Tecnológica, v. 12, n. 1, p. 97-108, 2018.

BARBARO, K.C. et al. Comparative study on extracts from the tissue covering the stingers of freshwater (Potamotrygon falkneri) and marine (Dasyatis guttata) stingrays. Toxicon, v. 50, p. 676-687, 2007.

BARBIER, R. A pesquisa-ação. Tradução de Lucie Didio. Brasília: Liber Livro Editora, 2007.

BARBOSA, I.R. Aspectos clínicos e epidemiológicos dos acidentes provocados por animais peçonhentos no estado do Rio Grande do Norte. Revista Ciência Plural, v. 1, n. 3, p. 2-13, 2015.

BARDIN, L. Análise de conteúdo. São Paulo: Edições 70, 2011.

BELLUCO, A.; CARVALHO, A.M.P. Uma proposta de sequência de ensino investigativa sobre quantidade de movimento, sua conservação e as leis de Newton. Caderno Brasileiro de Ensino de Física, v. 31, n. 1, p. 30-59, abr. 2014.

BELTRAME, V.; D'AGOSTINI, F.M. Acidentes com animais peçonhentos e venenosos em idosos registrados em municípios do estado de Santa Catarina, Brasil. Revista Brasileira de Ciências do Envelhecimento Humano, v. 14, n. 3, 2017.

BERNARDE, P.S. Anfíbios e répteis: introdução ao estudo da herpetofauna brasileira. Curitiba: Anolis Book, 2012.

BERNARDE, P.S. Serpentes peçonhentas e acidentes ofídicos no Brasil. São Paulo: Ed. Anolisbooks, 2014.

BONASSINA, A.L.B.; KUROSHIMA, K.N. Impactos do ensino, pesquisa e extensão universitária: instrumento de transformação socioambiental. Revista Brasileira de Educação Ambiental, v. 16, n. 1, p. 163-180, 2021.

BRANDÃO, R.A.; FRANÇOSO, R.D. Acidente por Rhopalurus agamemnon (koch, 1839) (Scorpiones, Buthidae). Revista da Sociedade Brasileira de Medicina Tropical, v. 43, n. 3, p. 342-344, 2010.

BRASIL. Lei no 10.406, de 10 de janeiro de 2002. Institui o Código Civil. Diário Oficial da União: seção 1, Brasília, DF, ano 139, n. 8, p. 1-74, 11 jan. 2002. 
BRITO, L.M.D. Elementos de influência no apego ao lugar de destino pelos turistas em Minas Gerais. 2019. 95f. Tese (Doutorado em Administração de Empresas) - Escola de Administração de Empresas, Fundação Getúlio Vargas.

CARDOSO, J.L.C. José de Anchieta e as Cartas. In: CARDOSO, J.L. et al. (Org.). Animais peçonhentos no Brasil: biologia, clínica e terapêutica dos acidentes. São Paulo: Sarvier, 2003.

CORRÊA, Y.G.; SEIBERT, C.S. A relação entre o ser humano e a arraia de água doce: duas faces de uma mesma moeda. Ambiente \& EducaçãoRevista de Educação Ambiental, v. 21, n. 1, p. 173-194, 2016.

CORRÊA, Y.G.; SEIBERT, C.S. Uso do Storytelling na educação ambiental para sensibilizar crianças sobre as arraias de água doce. Ambiente \& Educação de Educação Ambiental, v. 24, n. 1, p. 3-31, 2019.

COSTA, C.C.; BÉRNILS, R.S. Répteis do Brasil e suas unidades federativas: lista de espécies. Revista Eletrônica Herpetologia Brasileira, São Paulo, v. 8, n. 1, p. 11-57, 2018.

COTTA, G.A. Animais peçonhentos. $5^{\underline{a}}$ ed. Belo Horizonte: Fundação Ezequiel Dias, 2014.

ENGEL, G.I. Pesquisa-ação. Educar, Curitiba: Editora da UFPR, n. 16, p. 181191, 2000.

ESPOSITO, L.A. et al. Systematic revision of the neotropical club-tailed scorpions, Physoctonus, Rhopalurus and Troglorhopalurus, revalidation of Heteroctenus, and descriptions of two new genera and three new species (Buthidae: Rhopalurusinae). Bulletin of the American Museum of Natural History, n. 415, 134 p., 2017.

FRANÇA, F.O. de S. et al. Acidente botrópico. In: CARDOSO, J.L. et al. (Org.). Animais peçonhentos no Brasil: biologia, clínica e terapêutica dos acidentes. São Paulo: Sarvier, 2003.

FRANCO, M.A.S. Pedagogia da pesquisa-ação. Educação e Pesquisa, v. 31, n. 3, p. 483-502, 2005.

REITAS, D.C. de et al. Serpentes: é possível conviver com elas? Revista Brasileira de Ecoturismo, v. 3, n. 3, p. 572-586, 2020.

FREITAS, M.A. Serpentes brasileiras. Lauro de Freitas: Malha-de-SapoPublicações, 2003.

GARRONE NETO, D.; HADDAD JÚNIOR, V. Arraias em rios da região Sudeste do Brasil: locais de ocorrência e impactos sobre a população. Revista da Sociedade Brasileira de Medicina Tropical, v. 43, p. 82-88, 2010.

GARRONE NETO, D.; SAZIMA, I. Stirring, Charging, and Picking: hunting tactics of potamotrygonid rays in the upper Paraná River. Neotropical Ichthyology, v. 7, n. 1, p. 113-116, 2009. 
GIL, A.C. Como elaborar projetos de pesquisa. $5^{a}$ ed. reimpr. São Paulo: Atlas, 2010.

GOPALAKRISHNAKONE, P. et al. Scorpion Venom; Springer: Berlin, Germany, 2015.

HADDAD JÚNIOR, V. Atlas de Animais Aquáticos Perigosos do Brasil: guia médico de identificação e tratamento. São Paulo: Editora Rocca, 2000.

HADDAD JÚNIOR, V. et al. Freshwater Stingrays: study of epidemiologic, clinic and therapeutic aspects based on 84 envenomings in humans and some enzymatic activities of the venom. Toxicon, v. 43, n. 3, p. 287-94, 1 Mar. 2004.

HALSTEAD, B.W. Poisonous and Venomous Marine Animals of the World. Gov. Print Office, v. 3, p. 29-69, 1970.

IBGE, Instituto Brasileiro de Geografia e Estatística. Biomas continentais do Brasil. 2019. Disponível em: <https://www.ibge.gov.br/geociencias/informacoes-ambientais/15842biomas. $\mathrm{html}$ ?edicao=16060\&t=downloads $>$. Acesso em: 15 nov. 2019.

INSTITUTO BUTANTAN. Acidentes por animais peçonhentos. São Paulo, 2007. Disponível em: <http://www.butantan.gov.br/perguntas.htm>. Acesso em: 20 dez. 2016.

KELLERT, S.R. Children's Attitudes, Knowledge and Behaviors Toward Animals. Fase IV. Washington, D.C., US. Fish and Wildlife Service, Department of Interior. ERIC Document Reproduction Service, v. 41, n. 237, 1984.

LAMEIRAS, J.L.V. et al. Arraias de água doce (Chondrichthyes Potamotrygonidae): biologia, veneno e acidentes. Scientia Amazonia, v. 2, n. 3, p. 11-27, 2013.

MARCHAND, P.; RATINAUD, P. L'analyse de similitude appliqueé aux corpus textueles: les primaires socialistes pour l'election présidentielle française. Actes des 11eme Journées internationales d'Analyse statistique des Données Textuelles, Liège, Belgique: Jadt, p. 687-699, 2012.

MARTINS, M.R. et al. Escorpiões: biologia e acidentes. Revista Científica Eletrônica de Medicina Veterinária, ano VI, n. 10, 2008.

MESSEDER NETO, H.S.; PINHEIRO, B.C.S; ROQUE, N.F. Improvisações teatrais no ensino de Química: interface entre teatro e ciência na sala de aula. Química Nova na Escola, v. 35, n. 2, p. 100-106, maio 2013.

MEYER, D.D.; DA SILVA, K.V.C. L. Brincar e filosofar, despertando o interesse pelo saber: oficinas sobre animais peçonhentos. Cadernos do Aplicação, v. 21, n. 1, p. 179-191, 2008.

MONACO, L.M.; MEIRELES, F.C.; ABDULLATIF, M.T.G.V. (Org.). Animais venenosos: serpentes, anfíbios, aranhas, escorpiões, insetos e lacraias. $2^{\mathrm{a}}$ ed. rev. ampl. São Paulo: Instituto Butantan, 2017. 
MOREIRA, L.M.; MARANDINO, M. Teatro de temática científica: conceituação, conflitos, papel pedagógico e contexto brasileiro. Ciênc. Educ., Bauru, v. 21, n. 2, p. 511-523, 2015.

NASCIMENTO, A.T.B. da S.; SANTOS, I.F.; NUNES, J.R.V. Oficinas educativas/reflexivas e a interface com saúde e o meio ambiente. Revista em Extensão, v. 18, n. 1, p. 134-144, 2019.

OLIVEIRA, A.T. de et al. Relação entre as populações naturais de arraias de água doce (Myliobatiformes: Potamotrygonidae) e pescadores no Baixo Rio Juruá, Estado do Amazonas, Brasil. Biota Amazônia, Macapá, v. 5, n. 3, p. 108-111, 2015.

OLIVEIRA, R.M. de et al. Escorpionismo na área urbana de Palmas Tocantins. Hygeia, v. 16, p. 137-158, 2020.

PASSOS, D.C. et al. Calangos e lagartixas: concepções sobre lagartos entre estudantes do Ensino Médio em Fortaleza, Ceará, Brasil. Ciência \& Educação, Bauru, v. 21, n. 1, p. 133-148, 2015.

PEREIRA, A.F. Design para a sustentabilidade: melhoria de produtos e processos e valorização da identidade local. Estudos em Design, Rio de Janeiro, v. 20, n. 2, p. 1-15, 2012.

PESSÔA, V.L.S. Ação do estado e as transformações agrárias no Cerrado das zonas de Paracatu e Alto Paranaíba. 1988. 239f. Tese (Doutorado em Geografia) - Universidade Estadual Paulista.

PIAGET, J. A formação do símbolo na criança: imitação, jogo e sonho imagem representação. Tradução de Álvaro Cabral e Christiano Monteiro. 3a ed. Rio de Janeiro: LTC. Título original: La Formation du Sembole chez l'enfant imitation, Jeu et Rêve, image et Représentation. Suíca: Editions Delachaux et Niestlé, Neuchâtel do da terceira edição, 1964.

PICHETH, S.F.; CASSANDRE, M.P.; THIOLLENT, M.J.M. Analisando a pesquisa-ação à luz dos princípios intervencionistas: um olhar comparativo. Educação, v. 39, n. Esp, p. s3-s13, 2016.

PRUDENTE, S.R. Educação Ambiental e escola de Educação Infantil: mapeando propostas e perspectivas. 2013. 149f. Dissertação (Mestrado em Sociedade, Tecnologia e Meio Ambiente) - Centro Universitário de Anápolis.

RIBEIRO NETO, D.G. et al. Escorpiões: um estudo de caso com estudantes do Ensino Fundamental. Revista de Ensino, Educação e Ciências Humanas, v. 21, n. 3, 2020.

RUSSELL, F.E. Venom Poisoning. Rational drug therapy, v. 5, n. 8, p. 1-7, 1971.

SANTOS, L.P. A relação da Geografia e o conhecimento cotidiano vivido no lugar. Geografia Ensino \& Pesquisa, v. 16, n. 3, p. 107-122, 2012. 
SCHMIDT, G.O. Levantamento dos escorpiões (Arachnida: Scorpiones) na Restinga da Praia da Pinheira, Palhoça, Santa Catarina, Brasil. 2008. $45 f$. Trabalho de Conclusão de Curso (Bacharel em Ciências Biológicas) Universidade Federal de Santa Catarina.

SILVA, A.W.P. et al. Concepções sobre serpentes entre jovens estudantes do Ensino Médio: um diálogo entre ciência e cultura. Scientia Plena, v. 12, n. 6, 2016.

SINAN, Sistema de Informação de Agravos de Notificação. Ministério da Saúde do Brasil, Secretaria do Sistema Departamento, Coordenação do Sistema Registro no INPI N.000000-0. 2017. Disponível em: <http://portalsinan.saude.gov.br/>. Acesso em: 05 ago. 2021.

SOUZA, L.B. Hipérbole mercantil da expansão urbana e suas implicações ambientais. Mercador, Fortaleza, v. 14, n. 4, p. 159-180, 2015.

STEDILE, N.L.R.; CAMARDELO, A.M.P.; CIOATO, F.M. Educação Ambiental no ensino formal para o correto manejo de resíduos. Revista Brasileira de Educação Ambiental, v. 16, n. 1, p. 96-113, 2021.

THIOLLENT, M. Metodologia da pesquisa-ação. São Paulo: Cortez, 2011.

TRAJANO, E. Políticas de conservação e critérios ambientais: princípios, conceitos e protocolos. Estudos Avançados, v. 24, n. 68, p. 135-146, 2010. 